\title{
The Density Determination of Small Solid Objects by a Simple Float Method-1
}

\author{
Randall M. Schoonover* \\ National Bureau of Standards, Washington, DC 20234 \\ January 20, 1982
}

\begin{abstract}
The density determination of a small solid object with a mass of only a few hundred milligrams is always a difficult and often an ellusive measurement. The advent of highly accurate hydrostatic weighing techniques and the density scale based on solid objects are utilized in a two liquid float method presented here that incorporates the advantages of this technology. The resulting measurement is an absolute determination of density with an uncertainty of $500 \mathrm{ppm}$ and has a density range from $2.3 \mathrm{~g} / \mathrm{cm}^{3}$ (silicon) to 21.5 $\mathrm{g} / \mathrm{cm}^{3}$ (platinum). The instrument was used to measure the variation in the alloy density of nickel with respect to phosphorus content and to determine the density of optical fiber glass.
\end{abstract}

Key words: density measurement; float method; small solid objects; solid object density scale.

\section{Introduction}

The density determination of a small solid object with a mass of only a few hundred milligrams is always a difficult and often an ellusive measurement. The advent of highly accurate hydrostatic weighing techniques $[1,2]^{1}$ and the density scale based on solid objects $[3,4]$ are utilized in a two liquid float method presented here that incorporates the advantages of this technology. The resulting measurement is an absolute determination of density with an uncertainty of $500 \mathrm{ppm}$ and has a density range from $2.3 \mathrm{~g} / \mathrm{cm}^{3}$ (silicon) to $21.5 \mathrm{~g} / \mathrm{cm}^{3}$ (platinum). The instrument was used to measure the variation in the density of nickel alloys with respect to phosphorus content [9] and to determine the density of "optical-fiber" glass.

\subsection{Background}

In 1923 Foulck [5] suggested that a float similar to an inverted hydrometer would be very sensitive to fluid density changes when the larger portion of the float was immersed in a fluid immiscible with and of different density from the fluid surrounding the stem. Foulck did not foresee the scientific usefulness for such a device and the idea was not applied until H. A. Bowman (formerly of NBS) suggested its use to Franklin and Spal [6] for measuring the density ratio of small samples. An obvious

*Center for Absolute Physical Quantities, National Measurement Laboratory. ${ }^{1}$ Figures in brackets indicate literature references at the end of this paper. and very useful application of Foulck's float is to the absolute determination of density for small solid objects as reported here.

\section{The Method}

When the float of figure 1 is immersed in two immiscible liquids of different density the tare weight can be adjusted so that the float is brought into equilibrium. If the solid object, of density $\varrho_{G e}$, is removed from the float and replaced by another sample, of density $\varrho_{S i}$, and likewise a third object of $\varrho_{\mathrm{Ag}}$, and finally a fourth of sample, $\varrho_{X}$, and all but the object of density $\varrho_{\mathrm{Si}}$ have approximately equal mass, then new equilibrium positions in each case will be established if one of the two following conditions exist:

1. The density gradient in the fluid column is sufficiently large.

2. The geometry of the float possess sufficient compliance.

In practice these conditions can be varied to control the range and sensitivity of the float. The equilibrium equations given below correspond to four cathetometer observations, $O_{\mathrm{Ge}}, O_{\mathrm{Si}}, O_{\mathrm{Ag}}$, and $O_{\mathrm{X}}$, of the float's relative elevation, where $O_{\mathrm{Ge}}-O_{\mathrm{Si}}=L_{1}-L_{3}$ and $O_{\mathrm{Ge}}$ $-O_{\mathrm{Ag}}=L_{1}-L_{7}$ etc.

$$
\begin{array}{r}
\mathrm{g}\left[G e-\varrho_{L} V_{G e}+F-\varrho_{L} V_{F}+L_{1}-\varrho_{L} V_{L 1}+L_{2}-\varrho_{H} V_{L 2}\right] \\
=0 \text { corresponds to } 0_{\mathrm{Ge}}
\end{array}
$$




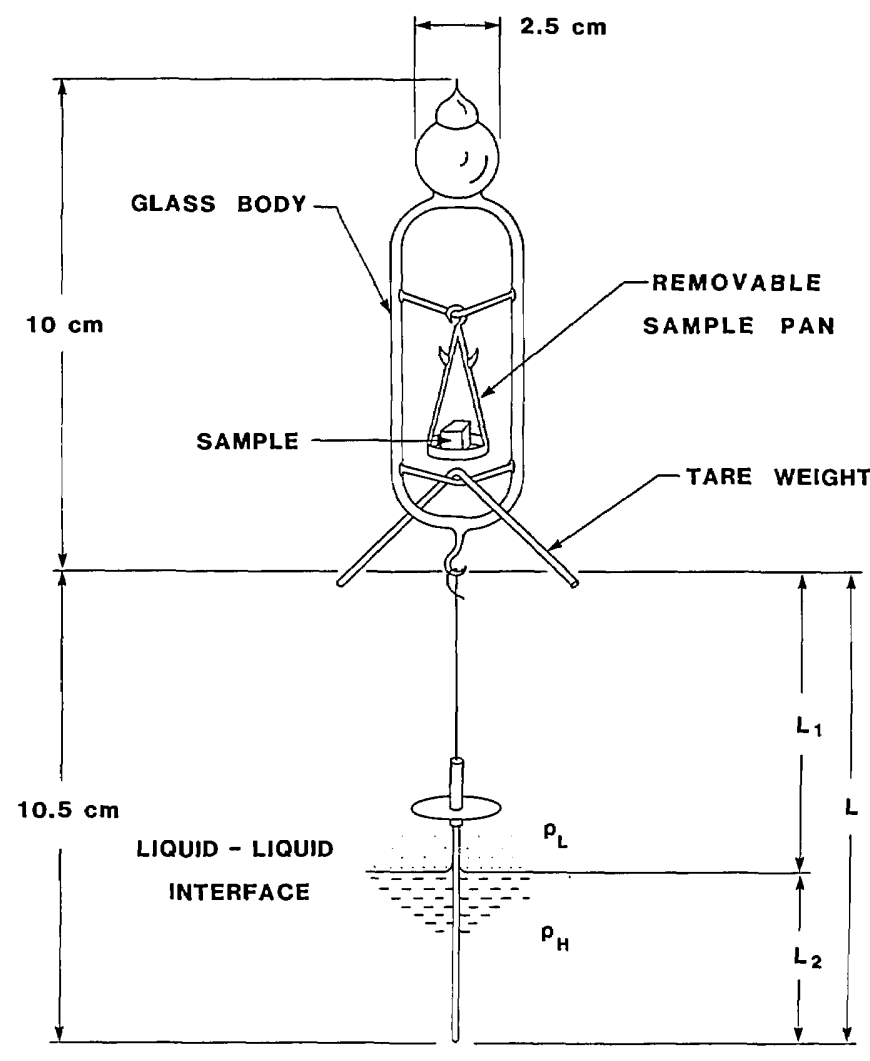

FIGURE 1: A sketch of the float assembly showing all of the components in the proper proportion.

$$
\begin{array}{r}
\mathrm{g}\left[\mathrm{Si}-\varrho_{L} V_{\mathrm{Si}}+F-\varrho_{L} V_{F}+L_{3}-\varrho_{L} V_{\mathrm{L} 3}+L_{4}-\varrho_{H} V_{L 4}\right] \\
=0 \text { corresponds to } O_{\mathrm{Si}}
\end{array}
$$$$
\begin{aligned}
\mathrm{g}\left[\mathrm{Ag}-\varrho_{L} V_{\mathrm{Ag}}+F-\varrho_{L} V_{F}+\mathrm{L}_{7}-\varrho_{L} V_{L 7}+L_{8}-\varrho_{H} V_{L 8}\right] \\
=0 \text { corresponds to } O_{\mathrm{Ag}}
\end{aligned}
$$

$$
\begin{array}{r}
\mathrm{g}\left[X-\varrho_{L} V_{X}+F-\varrho_{L} V_{F}+L_{5}-\varrho_{L} V_{L 5}+L_{6}-e_{H} V_{L 6}\right] \\
=0 \text { corresponds to } O_{\mathrm{X}}
\end{array}
$$

The terms $\mathrm{Ge}, \mathrm{Si}, \mathrm{Ag}$ and $\mathrm{X}$ are the sample masses corresponding to the volumes $V_{\mathrm{Ge}}, V_{\mathrm{Si}}, V_{\mathrm{Ag}}, V_{\mathrm{X}}$ with the subscripted $L$ terms representing the mass of the float stem sections above and below the liquid-liquid interface. The less dense liquid has a density of $\varrho_{L}$, and the more dense, $\varrho_{H}$. Common to each equation are the forces acting on the float body, $g\left(F-\varrho_{L} V_{F}\right)$, where $F$ and $V_{F}$ are the mass and volume of the float respectively. Equations (1), (3), and (4) are reduced for the unknown volume, $V_{\mathrm{X}}$ where:

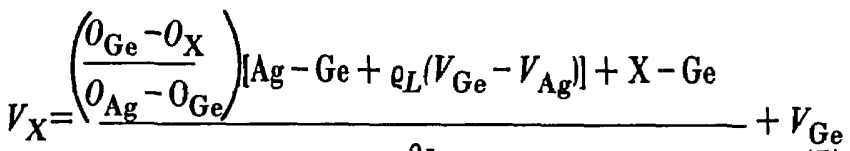

$\ell_{L}$
The term, $\varrho_{L}$, appears twice in eq (5) and can be determined independently by solving eqs (1), (2), and (3) with the following result:

$\varrho_{L}=\frac{(\mathrm{Ge}-\mathrm{Ag})\left(O_{\mathrm{Si}}-O_{\mathrm{Ge}}\right)+\left(O_{\mathrm{Ag}}-O_{\mathrm{Ge}}\right)(\mathrm{Si}-\mathrm{Ge})}{\left(O_{\mathrm{Si}}-O_{\mathrm{Ge}}\right)\left(V_{\mathrm{Ge}}-V_{\mathrm{Ag}}\right)-\left(O_{\mathrm{Ag}}-O_{\mathrm{Ge}}\right)\left(V_{\mathrm{Ge}}-V_{\mathrm{Si}}\right)}$

If the sample masses are sufficiently close then eq (5) reduces to a simpler form eliminating the need to know $\varrho_{L}$ as follows:

$V_{\mathrm{X}}=\left(\frac{O_{\mathrm{Ge}}-o_{\mathrm{X}}}{O_{\mathrm{Ag}}-O_{\mathrm{Ge}}}\right)\left(V_{\mathrm{Ge}}-V_{\mathrm{Ag}}\right)+V_{\mathrm{Ge}}$

For this work, the densities $\varrho_{\mathrm{Ge}}$ and $\varrho_{\mathrm{Ag}}$ are such that $\varrho_{\mathrm{Ge}}<\varrho_{\mathrm{X}}<\varrho_{\mathrm{Ag}}$, with the instrument range thus being established only in the region between $\varrho_{\mathrm{Ge}}$ and $\varrho_{\mathrm{Ag}}$. In practice the range in density from $2.3 \mathrm{~g} / \mathrm{cm}^{3}$ for $\mathrm{Si}$ and $21.5 \mathrm{~g} / \mathrm{cm}^{3}$ for $\mathrm{Pt}$ should include fixed points at 5.3 $\mathrm{g} / \mathrm{cm}^{3}$ (Ge), $10.4 \mathrm{~g} / \mathrm{cm}^{3}$ (Ag), and $16.6 \mathrm{~g} / \mathrm{cm}^{3}$ (Ta), or other suitable materials of similar densities.

A contradictory requirement is placed on the density standards $\varrho_{G e}, \varrho_{S i}$, and $\varrho_{A g}$ when used to determine, $\varrho_{L}$. Since the largest possible buoyant force difference is desired, therefore the sample fabricated from the least dense material, $\varrho_{S i}$, must have an increased mass that just permits an onscale equilibrium position. That is to say the objects, $\mathrm{Ge}, \mathrm{Ag}$, and $\mathrm{X}$ are approximately equal in mass, but the mass $\mathrm{Si}$ is significantly larger.

\section{Apparatus}

The success of the method described here requires that the apparatus be designed in such a manner as to make a difficult task manageable on a basis that routinely yields consistent and satisfactory results. It is the author's intent to give ample detail, at the expense of brevity, so the device can be duplicated successfully and without great pain by anyone desiring to do so.

\subsection{Choosing the Liquids}

Fluorocarbon compounds have been used in density measurements for many years [4] because they are inert, their $1.8 \mathrm{~g} / \mathrm{cm}^{3}$ density increases the buoyant force compared to distilled water, they have a low surface tension, and they are not miscible with many common solvents. The requirements necessary for the two liquids used in this application are:

1. extremely low miscibility,

2. low interfacial surface tension and,

3. a large difference in their densities. 
A liquid manufactured by the $3 \mathrm{M}$ company designated FC- $43^{2}$ was chosen as the denser liquid $\left(\varrho_{H}\right)$. The other liquid selected, methanol, $\left(\varrho_{L}\right)$ was chosen because it is reported to be immiscible with FC-43, meets the above requirements, and is not extremely hazardous. Early in the instrument development, the interfacial surface tension was measured between FC-75, a liquid with properties similar to FC-43 but not quite as desirable (for this application), and various solvents. Table 1 summarizes the results of that work. A few partially miscible liquids were measured to show that the interfacial surface tension decreases as the liquids partially mix. The interfacial surface tension data tend to verify the manufacturer's data regarding miscibility of various liquids with FC-75.

Although methanol was selected for use as the less dense liquid $\left(\varrho_{L}\right)$ for the work described here, other liquids should work and would be required if a sample to be measured is soluable in methanol.

\subsection{The Float}

In essence the float is comprised of several components. They are:

1. the main borosilicate glass body

2. sample pan

3. removeable nichrome wire stem assembly

4. tare weight.

Figure 1 is a scale view of the float and figure 2 shows a cross-sectional view of the apparatus proportional to the float.

\footnotetext{
${ }^{2}$ The identification of trade names and company products in this paper is to adequately specify the experimental conditions. Such identification does not imply recommendation or endorsement by the National Bureau of Standards nor does it imply that these materials are necessarily the best available for the purpose.
}

The main borosilicate glass body is blown from thin wall borosilicate tubing. The overall mass and displacement volume are made small for improved dynamic response and to provide for a small overall liquid system. Likewise, the sample pan is fabricated from borosilicate glass. The pan has two barbs to accommodate samples of large thin sheets suspended from pan bails.

A sten assembly was devised to permit its easy removal while keeping the float immersed and allows for changing the stem diameter, and hence the instrument range. The disc is captured on the stem by two heatshrinkable teflon bands as shown in figure 1. This feature prevents the float from rising to the surface during sample exchanges. A joint made of heat-shrinkable teflon permits coupling various diameters of treated nichrome wire [2] for making significant changes in sample mass or float sensitivity. The portion of wire above the joint either remains unchanged or is made nearly identical for each stem assembly.

\subsection{Wire Treatment}

Those experienced in hydrostatic weighing know the beneficial value of an oxide coating placed on the suspension wire that penetrates the air-water interface and connects the immersed load to the balance above. Early experimentation with float and wire stems of 0.008 and 0.012 in. diameter has indicated that coated stems significantly improved the precision as opposed to bare wire stems. Although the coating of nichrome wire is discussed by Bowman and Schoonover, [2], the float application has additional considerations to be concerned with.

In ordinary hydrostatic weighing the coated suspension wire is under enough tension to remove any curvature present, a wire 0.008 inch diameter will safely

TABLE 1. Interfacial surface tension between FC-75 and various liquids considered for the apparatus. The water FC-75 interfacial surface tension was very large and unmeasurable by the apparatus used.

\begin{tabular}{lccc}
\hline \hline Liquid & Specific Gravity & Surface Tension & Interfacial Tension \\
\hline Methanol $^{\mathrm{b}}$ & 0.79 & 22.6 dynes/cm & 11.0 dynes/cm \\
Isopropyl $^{\mathrm{b}}$ & .68 & 21.7 & 6.5 \\
Toluene $_{\text {Benzene }}$ & .87 & 28.4 & 8.0 \\
Trichloroethylene $_{\text {Acetone }}$ & .87 & 28.9 & 9.0 \\
Hexane $^{\mathrm{a}}$ & 1.47 & & 4.5 \\
Heptane $^{\mathrm{a}}$ & 0.79 & 23.7 & 7.5 \\
Water $^{\mathrm{b}}$ & .66 & 18.4 & 1.0 \\
FC-75 & .68 & & 2.2 \\
\hline
\end{tabular}

Partially miscible.

bAccording to the manufacturer not miscible with FC-43. 


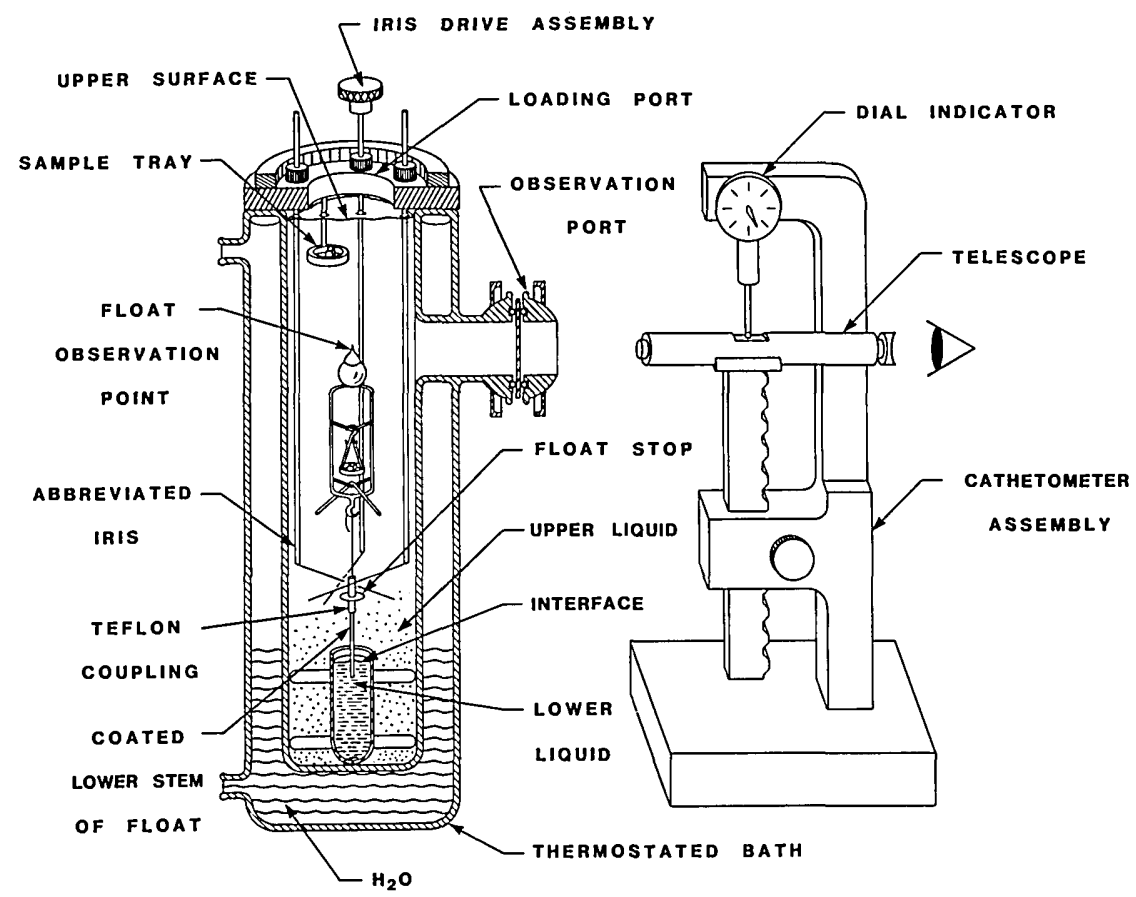

FIGURE 2: An overall schematic view of the density apparatus showing the float proportional to the surrounding chamber.

support a one kilogram mass, and therefore large diameters are not required. The float application here requires the wire to be inherently straight and as a practical matter a wire diameter of 0.062 inch may be desirable. The method of Bowman and Schoonover consists of heating the wire to $800^{\circ} \mathrm{C}$ in a vacuum (about 50 $m$ Torr) by passing an electrical current through the wire. For the small-diameter wire (0.008-0.020 inch) it was necessary to construct a treatment chamber, as shown in figure 3, that keeps the wire in tension during the coating process, resulting in straight wire suitable for use as a float stem.

Larger diameter wires of 0.020 inch diameter and above required a different approach altogether. These large wires were straightened by stretching the wire beforehand. This was accomplished by reversing the action of a machine shop press. Coating then followed in a chamber designed to open at both ends and to have electrical connectors of higher current capacity. An autotransformer with a $20 \mathrm{~A}$ current rating is necessary for heating the larger wires. Near the completion of this work it was discovered the 0.062 inch wire could be coated successfully by merely heating the wire in air, periodically interrupting the process to view the coating density, and then terminating the heating when the coating appears correct (a very uniform pattern such as bark on a tree or a mountain range viewed from high altitudes). Future work may show that heating the wire in vacuum is only required for the smaller diameters.
The desired stem diameter, in centimeters, is calculated for a specified sample mass and density range as follows:

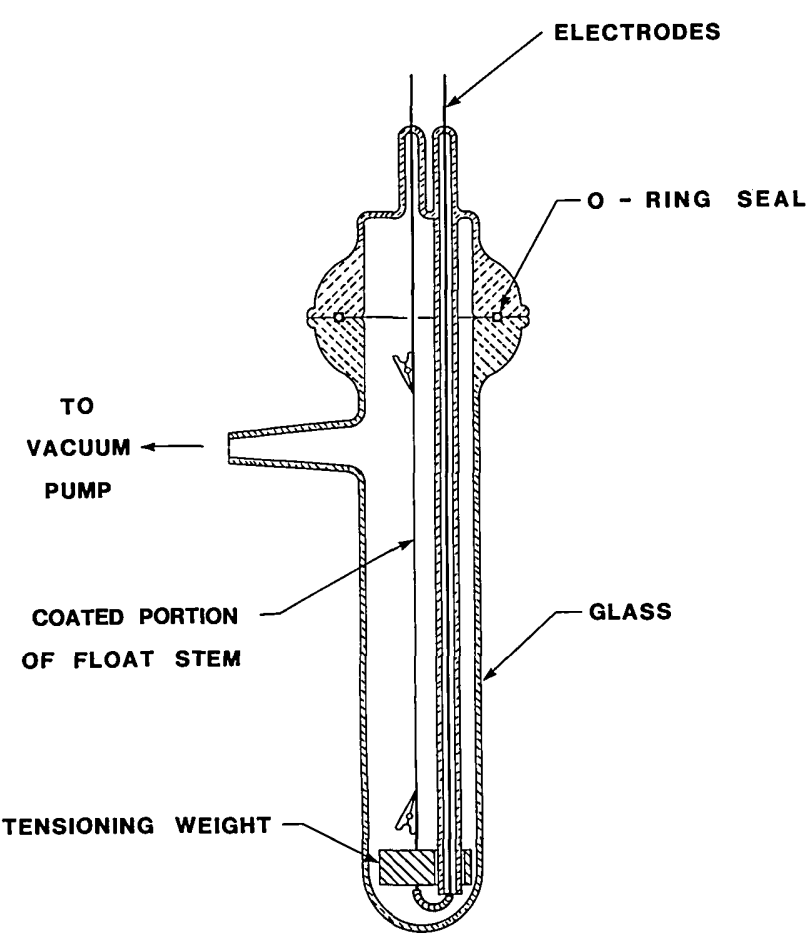

Figure 3: Float stem fabrication chamber. 


$$
\text { Dia. }=2\left(\frac{\varrho_{L} \Delta V}{2.54 \pi\left(\varrho_{H}-\varrho_{L}\right)}\right)^{1 / 2}(\mathrm{~cm})
$$

where $\Delta V$ is the difference in volume between the least dense and most dense standard and, 2.54, is the cathetometer range in centimeters.

\section{EXAMPLE 1:}

For $0.3 \mathrm{~g}$ standards of $\varrho=2.379 \mathrm{~g} / \mathrm{cm}^{3}$ and $\varrho=5.327$ $\mathrm{g} / \mathrm{cm}^{3}$ and liquid densities of $\varrho_{L}=0.79 \mathrm{~g} / \mathrm{cm}^{3}$ and $\varrho_{H}$ $=1.88 \mathrm{~g} / \mathrm{cm}^{3}$ the difference in volume is

$$
\Delta V=0.3\left(\frac{1}{2.329}-\frac{1}{5.327}\right)=.0725 \mathrm{~cm}^{3}
$$

and the stem diameter is

Dia. $=2\left(\frac{0.79 \times 0.0725}{2.54 \pi \times 1.09}\right)^{1 / 2}=0.162 \mathrm{~cm}(0.064 \mathrm{in})$

The precision in density measurements of a mass, $X$, which can reasonably be expected from such a wire can be estimated from the following formula:

$$
\text { Precision } \simeq \frac{\varrho_{x}}{X} \frac{W\left(\varrho_{H}-\varrho_{L}\right)}{\varrho_{L}} \times 3 R
$$

where $W$ is the cross-sectional area of the chosen wire and $R$ is the precision of the cathetometer reading.

\section{EXAMPLE 2:}

For a $0.2 \mathrm{~g}$ sample of unknown density $e_{x} \sim 2.3$ $\mathrm{g} / \mathrm{cm}^{3}$ ), wire diameter $0.162 \mathrm{~cm}$, and cathetometer precision $5 \times 10^{-4} \mathrm{~cm}$ the expected precision of a measurement of the unknown density is

$$
\begin{aligned}
\text { Precision } & \simeq \frac{2.3}{0.2} 2.8 \times 10^{-2} \frac{(1.88-0.79)}{0.79} \times 3 \times 5 \times 10^{-4} \\
& \simeq 7 \times 10^{-4} \text { or } \pm 0.002 \mathrm{~g} / \mathrm{cm}^{3}
\end{aligned}
$$

\subsection{Tare Weights}

Any major change in operating temperature, float sensitivity, or capacity requires a change in the tare weight, which is readily fabricated from nichrome wire. Each weight is adjusted so that when the float is loaded with the least dense and then the most dense standards, the float tip remains in view through the optical window.

\subsection{The Iris Diaphragm}

A very important part of the apparatus is the abbreviated iris diaphragm formed by three equally spaced shafts. Each shaft is connected to a ring gear (with internal teeth) by a pinion gear. Thus, driving one shaft causes all three to rotate simultaneously and thereby open or close the wire fingers at the other end. One of these shafts is supported in an eccentric teflon journal bearing that can be rotated to reduce the backlash of all three pinion gears with the ring gear. The iris assembly is visible in figure 2.

Not only does the iris when closed prevent the float stem from leaving the lower liquid completely when the pan is removed from the float but it also serves to center the float after reloading. Details on its use are covered in a later section.

\subsection{Liquid Cup}

It is a very desirable feature of the apparatus to place the FC-43 liquid in a cup that is only a small portion of the surrounding bath volume. Earlier versions of the instrument required difficult and periodic cleaning of the liquid interface. This difficulty is avoided by use of a cup that was found to be self-cleaning if filled to the upper rim with FC-43. Therefore, a cup was designed that could be filled externally and lowered in place by a removeable wire bail. A stream of FC-43 is then released from a syringe from above and the droplets pass through the methanol completing the filling operation. The cup was made with a slight depression in the rim that allows foreign particles to be swept away by turbulence and immediately settle in the less dense methanol. FC-43 is very expensive and its recovery is economically desirable. The cup has the additional advantage of keeping the volume of FC-43 small and easily recoverable.

\subsection{Temperature-Controlled Bath}

Surrounding the float chamber is an outer container of borosilicate glass [4] that is fused at the top to the inner chamber. Figure 2 shows the cross-sectional view of the bath. An optical window with a $3 \mathrm{~cm}$ aperture for viewing the float tip was devised by fusing an " $O$ "-ring connector at the proper location to the chamber and clamping a window between a teflon " $O$ "-ring on the inside and an ordinary " $O$ "-ring on the outside, as shown in Figure 2. This arrangement is readily disassembled for cleaning and the seal is virtually impervious to common solvents.

Two additional " $O$ "-ring connections provide ports for circulating temperature controlled water capable of holding the bath temperature to $\pm 0.003{ }^{\circ} \mathrm{C} / \mathrm{hr}$. When 
the temperature controlled water is initially circulated an air pocket is trapped between the jacket wall at the very top and provides a damping effect on pump pulsation.

\subsection{Cathetometer}

A cathetometer was devised by mounting a dial indicator above a microscope mounted on a vertical guide. The device is shown schematically in figure 2 . The microscope contains a "cross-hair" reticle for sighting on the float tip and has a magnification of 15 diameters. The system is back lighted with green light to improve the image.

The dial indicator has a range of 1 in $(2.54 \mathrm{~cm})$ and can resolve displacements of 0.0001 in with a nonlinearity less than 0.0001 and a precision of 0.0002 in. The dial indicator can be checked by inserting gauge blocks on the platen under the indicator stylus.

\section{Sample Handling}

To exchange samples carried on the float, the iris is first closed and the pan then removed with a long piece of stiff wire bent to form a V-shaped hook on the immersed end. Several such tools were fabricated from 0.032 inch stainless steel welding rods. The pan was placed on a loading platform (just under the methanol surface) and trapped in a recess such that the pan rim is flush with the sample storage surface. Then samples stored on the same support can be exchanged. This required that a forcep be designed (see fig. 4) for operation through a small aperture. The resulting tool can be opened by pushing the upper end down or closed by pushing the tubular body down. This forcep design has proved to be a great asset to the overall success of the measurement. Observe in figure 4 , that the open end of the forceps allows for grasping most irregular shapes.

A storage rack of wire hooks on a cross-tree provides a means to store samples in the form of thin sheets by simply cutting a small hole in the sheet.

\subsection{Sample Preparation}

The standard objects of single crystal silicon, germanium, and silver were acid etched in the appropriate manner to remove work damage, thereby permitting both inspection for cracks that may result from the cutting process and adjustment of the mass. Glass and ceramic samples after cutting can be brought to the desired mass by various abrasion techniques. The extremely thin and brittle nickel-phosphorous alloys were cut from 0.003 in sheets by machining with a high velocity abrasive stream (sand blasting).

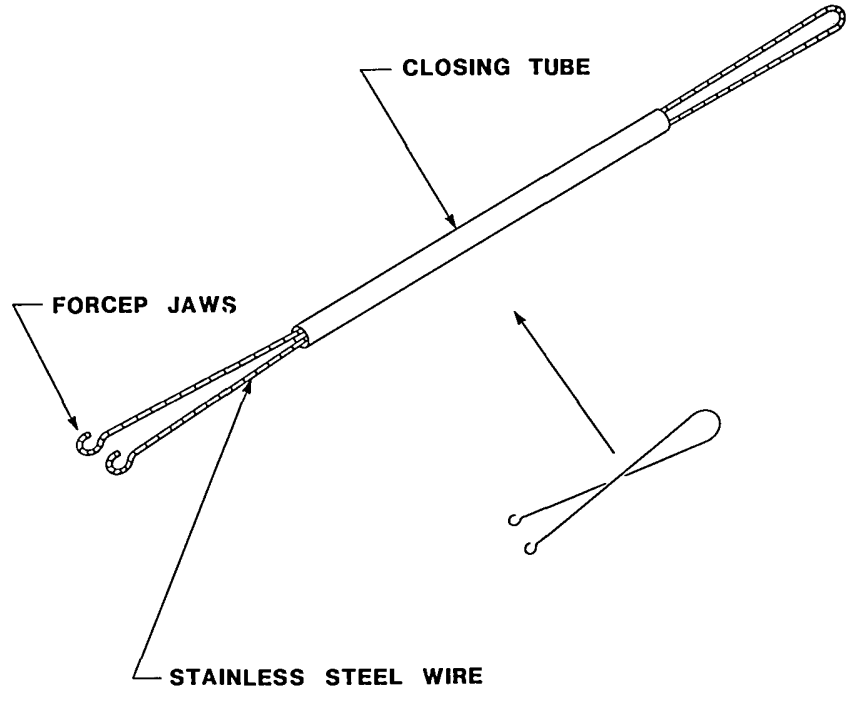

FIGURE 4: The single-handed, self-locking forcep designed for handling small solid samples.

When desired, the unknown sample mass can be adjusted to that of a density standard using a micro balance and the following equation that accounts for the buoyant force of air:

$$
M_{\mathrm{Si}}\left[\left(1-\frac{\varrho_{a}}{\varrho_{X}}\right)-\left(1-\frac{\varrho_{a}}{\varrho_{\mathrm{Si}}}\right)\right]=\Delta M .
$$

$$
\text { Note: for } \varrho_{X}>\varrho_{S i}, \Delta M>0
$$

where $M_{\mathrm{Si}}$ is the mass of the density standard, $\varrho_{\mathrm{Si}} \cdot \varrho_{X}$ is the approximate density of the unknown object as determined from a mechanical measurement or a handbook. $\Delta M$ is the difference that would be indicated on a balance in air between the standard and unknown if these masses are equal in vacuum.

For example, if a silicon density standard having a mass of $0.300000 \mathrm{~g}$ is on hand and a germanium standard is to be fabricated to also have a mass of 0.300000 $\mathrm{g}$, then (as indicated by the balance in air) the germanium sample must be $87 \mu \mathrm{g}$ more than the silicon standard as calculated from the parameters given below:

$M_{\mathrm{Si}}=$ silicon mass of density, $\varrho_{\mathrm{Si}}\left(2.329 \mathrm{~g} / \mathrm{cm}^{3}\right)$.

$\varrho_{a}$, the density of air, is assumed to be $.00120 \mathrm{~g} / \mathrm{cm}^{3}$.

$\varrho_{X}$ is the approximate density of germanium 5.3 $\mathrm{g} / \mathrm{cm}^{3}$.

Sample masses can be adequately determined on appropriate analytical balances by the method given in [7]. This of course is necessary when one wishes to use the method of eq (5). 


\section{Test Method and Measurements}

Initial investigation revealed two measurement requirements: a measurement sequence that eliminated drift and a waiting period of about $6 \mathrm{~min}$ before a stable float position is reached after a sample exchange and before the cathetometer observation is made. The waiting period begins when the port opening is closed immediately upon changing float loads. During this period the iris restricts the float position but does not impinge on its freedom to oscillate vertically. Just prior to reading the cathetometer the iris is opened to approximate an equilateral triangle with a base of $1 \mathrm{~cm}$.

The weighing sequence used is illustrated as follows:

\begin{tabular}{lcl}
\hline \hline Object & Observation & \\
\hline Germanium std & $y_{1}$ & \\
Silicon std. & $y_{2}$ & $\mathrm{Ge}=1 / 2\left(y_{1}+y_{5}\right)$ \\
Silver std. & $y_{3}$ & $\mathrm{Si}=1 / 2\left(y_{2}+y_{4}\right)$ \\
Silicon std. & $y_{4}$ & $\mathrm{Ag}=y_{3}$ \\
Germanium std. & $y_{5}$ & \\
X $_{1}$ & $y_{6}$ & \\
Silver std. & $y_{7}$ & $\mathrm{Ge}=1 / 3\left(y_{5}+y_{9}+y_{13}\right)$ \\
$\mathrm{X}_{2}$ & $y_{8}$ & $\mathrm{Ag}=1 / 2\left(y_{7}+y_{11}\right)$ \\
Germanium std. & $y_{9}$ & $\mathrm{X}_{1}=1 / 2\left(y_{6}+y_{12}\right)$ \\
$\mathrm{X}_{2}$ & $y_{10}$ & $\mathrm{X}_{2}=1 / 2\left(y_{8}+y_{10}\right)$ \\
Silver std. & $y_{11}$ & \\
$\mathrm{X}_{1}$ & $y_{12}$ & \\
Germanium std. & $y_{13}$ & \\
\hline
\end{tabular}

Observations $y_{1}$ through $y_{5}$ determine, $\varrho_{L}$, and all but $y_{5}$ are omitted if the masses of all objects are nearly identical or an assumed value for $\varrho_{L}$ is used or both. The equations to the right of the sequence average the cathetometer observations for each object in the sequence. The subscripted $y$ terms, when averaged, correspond to the cathetometer observations in the equilibrium eqs (1), (2), (3), and (4).

\subsection{Precision}

For the initial precision test a stem diameter of 0.051 in wire was chosen to be used with $200 \mathrm{mg} \mathrm{Si}$ and $\mathrm{Ge}$ standards. The masses were adjusted close to each other, as were samples of uranium glass and lead glass. Three abbreviated measurement sequences were carried out using the method of eq (7). In the following results, the ranges were used to estimate the standard deviations, $S$.

\begin{tabular}{cc|c|c}
\hline \hline & \multicolumn{1}{c|}{ Test 1 } & Test 2 & Test 3 \\
\hline $\begin{array}{c}\text { Uranium } \\
\text { Glass } \\
\text { Lead } \\
\text { Glass }\end{array}$ & $2.2665 \mathrm{~g} / \mathrm{cm}^{3}$ & $2.6655 \mathrm{~g} / \mathrm{cm}^{3}$ & $2.2640 \mathrm{~S}=0.0015 \mathrm{~g} / \mathrm{cm}^{3}$ \\
\hline
\end{tabular}

These data indicate the method has a precision of about 6 parts in 10,000. Note that the precision achieved for uranium glass agrees well with the predicted value (see EXAMPLE 2 above).

\subsection{Linearity Test}

Although the author has no reason to believe that diedrawn nichrome wire is not uniform in diameter to 1 part in 10,000 or better, a linearity test was devised to test the assumption.

Two additional float-equilibrium equations can be written as follows:

$M_{1}-\varrho_{L} V_{M 1}+F-\varrho_{L} V_{F}+L_{1}-\varrho_{L} V_{L 1}+L_{2}-\varrho_{H} V_{L 2}=0 \approx 0_{1}$

$M_{2}-\varrho_{L} V_{M 2}+F-\varrho_{L} V_{F}+L_{3}-\varrho_{L} V_{L 3}+L_{4}-\varrho_{H} V_{L 4}=0 \approx 0_{2}$

The above can be put in the form where $M_{1}-M_{2}=$ $\Delta M$ and

$$
\frac{o_{1}-o_{2}}{\Delta M}=-\mathrm{K}\left[\frac{1+\frac{\varrho_{L}}{\varrho_{M}}}{\varrho_{L}-\varrho_{H}}\right]=\text { constant }
$$

The above is true if the density, $\varrho_{M}$, of both mass $M_{1}$ and $M_{2}$ is the same.

For the linearity test three silicon silicon crystal masses were fabricated and placed sequencially and in combination on the float pan as shown below. The float stem diameter was 0.062 in.

\begin{tabular}{l|c|c|c|c}
\hline \hline \multicolumn{5}{c}{ LINEARITY TEST } \\
\hline Sequence & $\begin{array}{c}\text { Cathetometer } \\
\text { Reading }\end{array}$ & $\Delta \mathrm{M}$ & $\begin{array}{c}\text { Calculated } \\
\text { Constant }\end{array}$ & Residuals \\
\hline Zero & 0.9898 & $0.022954 \mathrm{~g}$ & 11.144 & -0.009 \\
$\Delta M_{1}$ & 0.7342 & & & \\
Zero & 0.9903 & 0.036692 & 11.174 & 0.021 \\
$\Delta M_{2}$ & 0.5810 & & & -.012 \\
Zero & 0.9917 & 0.052390 & 11.141 & -.001 \\
$\Delta M_{3}$ & 0.4078 & & & \\
Zero & 0.9913 & 0.075344 & 11.152 & \\
$\Delta M_{4}$ & 0.1515 & & $\bar{X} 11.1528$ & \\
Zero & 0.9921 & & & \\
\hline
\end{tabular}

Examination of the above residuals does not show a correlation between $\Delta M$ and float position and that therefore the diameter of the wire is acceptably constant at the present level of precision.

\subsection{The measurement of "optical-fiber" glass}

The density of samples of "optical-fiber" glass were measured and the data are used to demonstrate the 
method where all masses are nearly equal (knowledge of $Q_{L}$ is not required). The density is then recalculated using the measured mass and an assigned value for $\varrho_{L}$ based on the bath temperature[8].

The results given below are based on two independent measurement sequences for each sample where a single crystal silicon and germanium are the standards. The sample masses were about $0.3 \mathrm{~g}$ and the stem diameter was 0.062 inch

\begin{tabular}{lcccc}
\multicolumn{5}{c}{ Method $\# 1$ (assuming equal masses $(0.299000 \mathrm{~g})$ - eq $(7)$} \\
Sample & $\mathrm{D} 14$ & $\mathrm{~B} 14(1132)$ & $\mathrm{B} 15(1072)$ & $\mathrm{B} 15(1076)$ \\
Density & $4.5464 \mathrm{~g} / \mathrm{cm}^{3}$ & 2.4908 & 2.4125 & 2.4091
\end{tabular}

Method \#2 (measured mass and assigned $Q_{L}$ ) - eq (5)

$\begin{array}{lllll}\text { Sample } & 4.5458 & 2.4915 & 2.4098 & 2.4108\end{array}$

Density Temperature, $21.5^{\circ} \mathrm{C}$

Assigned $\mathrm{Q} L=0.78991 \mathrm{~g} / \mathrm{cm}^{3}$

Method \#1 -Method \#2

$\begin{array}{llll}-0.0006 \mathrm{~g} / \mathrm{cm}^{3} & -0.0007 & +0.0027 & -0.0017\end{array}$

Sample Masses

Differences in Mass

Si $0.299900 \mathrm{~g}$

Ge 0.299885

D140.299866

B14(1132) 0.299859

B15(1072) 0.299906

B15(1076) 0.299842

$\mathrm{Si}-\mathrm{Ge}=+15 \mu \mathrm{g}$

$\mathrm{Si}-\mathrm{D} 14=+34 \mu \mathrm{g}$

$\mathrm{Si} \cdot \mathrm{B} 14(1132)=+41 \mu \mathrm{g}$

$\mathrm{Si}-\mathrm{B} 15(1072)=-6 \mu \mathrm{g}$

$\mathrm{Si}-\mathrm{B} 15(1076)=+58 \mu \mathrm{g}$

Differences as large as 1 part in 1000 in density do occur between the two methods, however the actual mass determination is avoided for all objects except the silicon standard in method \#1 and likewise the measurement of $\varrho_{L}$ is avoided. It will be shown later that handbook values for $Q_{L}$ agree well with the measured values and $\varrho_{L}$ could have been measured here merely as a check standard.

\subsection{Nickel Phosphorous Alloy Determination}

The Corrosion and Electrodeposition Group of the NBS submitted very small samples of nickel phosphorus alloy for which the density determination was very difficult. The success of these measurements thoroughly demonstrates the usefulness for scientific purposes of the method presented here.

The samples were fabricated by chemical deposition of nickel phosphorous alloy on a copper substrate. The substrate is then etched away leaving a very thin 10.003 in) plate that is extremely brittle and fragile. One aspect of the study was to correlate the alloy density with phosphorous content. The metallurgical significance of this work is reported by Ogburn et al. [9].
Sample preparation required the use of an abrasive machining process (sand blasting), to obtain samples in the approximate shape of a disc and a mass $0.2 \mathrm{~g}$. To facilitate their manipulation in the float chamber a $3 \mathrm{~mm}$ hole was machined in each disc. The mass of each sample was then adjusted to the sample of least mass by additional machining. The mass adjustment process was not easily controllable and wide variations were present in the final values.

It was necessary to use the more protracted measurement scheme; i.e. determine all of the masses and measure $e_{L} \cdot{ }^{3} \mathrm{~A} 0.042$ in dia. wire was selected for the float stem to increase the measurement sensitivity. Because the nickel phosphorous alloy has a density of $\approx 8.0 \mathrm{~g} / \mathrm{cm}^{3}$ it was necessary to determine the density of a boule of single crystal silver by hydrostatic weighing [2], thus providing a density standard of $10.492 \mathrm{~g} / \mathrm{cm}^{3}$. Single crystal germanium $\left(5.327 \mathrm{~g} / \mathrm{cm}^{3}\right)$ was the other standard used. A silicon crystal of $0.268 \mathrm{~g}$ provided the large buoyant force required to determine $\varrho_{L}$.

The full measuring sequence given previously was then used to assign values to the nickel alloys, no parameters being assumed. The data presented below are three independent determinations but do not include all of the results reported in [9]. The reader may recall there are two values for each unknown determined in the sequence, the mean value is reported here for each measurement.

\begin{tabular}{l|l|l|l|l}
\hline \multicolumn{5}{c}{ SAMPLE IDENTIFICATION } \\
\hline & NI42-7\% PH & NI24-9\% PH & NI50-10\% PH & NI56-10\% PH \\
\hline Meas. 1 & $8.201 \mathrm{~g} / \mathrm{cm}^{3}$ & $8.091 \mathrm{~g} / \mathrm{cm}^{3}$ & $8.044 \mathrm{~g} / \mathrm{cm}^{3}$ & $8.049 \mathrm{~g} / \mathrm{cm}^{3}$ \\
Meas. 2 & Outlyer & 8.088 & 8.052 & 8.059 \\
Meas. 3 & 8.207 & 8.083 & 8.047 & 8.061 \\
X & 8.204 & 8.087 & 8.048 & 8.056 \\
Std. & & & & \\
Dev. & 0.0053 & 0.0047 & 0.0047 & 0.0071 \\
\hline
\end{tabular}

NOTE: Std. Dev. was determined by the range method [10].

The sample masses were:

$\begin{array}{ll}\text { Si } & 0.268376 \mathrm{~g} \\ \text { Ge } & 0.199798 \\ \text { Ag } & 0.197764 \\ \text { NI24 } & 0.200167 \\ \text { NI42 } & 0.199496 \\ \text { NI50 } & 0.196077 \\ \text { NI56 } & 0.200613\end{array}$

The methanol densities, as determined from the above measurements, are as follows:

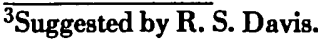




$$
\begin{gathered}
0.7897 \mathrm{~g} / \mathrm{cm}^{3} \text { at } 22.2^{\circ} \mathrm{C} \\
0.7902 \\
0.7901 \\
0.7903 \\
0.7899 \\
0.7899 \\
\bar{X}=.7900 \text { (handbook value } 0.7896 \mathrm{~g} / \mathrm{cm}^{3} \text { ) } \\
\text {. Std. Dev. }=0.0002
\end{gathered}
$$

On would expect a higher measured value than that given by the table due to absorbed water in the methanol (the table value is for pure methanol). An effort will be made in any future work to perform a Karl Fischer titration for an estimate of the absorbed water.

\section{Uncertainty of the method}

In considering the sources and effects of errors, the discussion will be limited to the method that includes the determination of $\varrho_{L}$ as well as the unknown sample masses. It is well documented by hydrostatic weighing $[1,2,4]$ and other float techniques [11] that the density of single crystal materials can be determined to better than $10 \mathrm{ppm}$ and the material is homogeneous to that level or better. This means errors in the volumes of the standards used here are almost entirely due to the mass determinations. If the material mass is greater than $100 \mathrm{mg}$, ordinary mass measurement methods [7] will not cause errors that exceed $10 \mu \mathrm{g}(100 \mathrm{ppm})$, which is well below the precision attained by the float method at this time. As the sample mass decreases the mass determination would have to be improved.

From an analysis one can conclude that the cathetometer-float system may have a basic limitation in the float hydrodynamics. However, a slight improvement may be gained with a more precise cathetometer. Since the uncertainty is due to both imprecision and insignificant systematic error, the uncertainty assigned to the nickel-phosphorous samples is taken to be 1 standard deviation.

\section{Conclusion}

The utilization of the solid object density scale, the ease and reliability of the technique make this method of measuring small sample densities attractive for general laboratory use.

Early in the development of this instrument the float. was assembled with a 0.010 in diameter wire and the results indicated the sample size can be decreased to 10 mg and still use the method reported here. However, a greater effort would be required in the mass determinations. Such small diameter stems would be quite useful if one were only interested in density ratios [12], a technique not investigated here.

Given the clear advantage of hindsight it seems unfortunate that isopropyl alcohol was not tested for use as the less dense liquid. The resulting lower interfacial surface tension may enhance the overall float performance.

Perhaps the overall performance could be improved with the proper choice of an additive to decrease the interfacial surface tension. Personal communication with M. R. Moldover suggest this may be contradictory if the fluids are to remain immiscible [13]. This area certainly requires some attention if the instrument performance is to be improved.

Many years ago Bowman and Schoonover [11] attached a magnet to their cartesian diver and sevoed it to a null position. Although the effort was successful for density ratios, it did not work to the desired $0.1 \mathrm{ppm}$. Perhaps using a magnet on the float here would eliminate the lower liquid and yield a precision 1 or 2 orders of magnitude improvement.

The author expresses gratitude to F. E. Jones for his assistance in checking the algebra and for the statistical analysis he provided. Thanks to R. S. Davis for checking algebra and for suggesting the methanol density determination; to Charles Reeve for the measurement sequence; and to James Taylor for the preparation of the artwork.

\section{References}

[1] Henins, I. J. Res. Nat. Bur. Stand. (U.S.). 68A(5): 529-533; 1964 September-October.

[2] Bowman, H.A.; Schoonover, R.M. Procedure for high precision density determinations by hydrostatic weighing. J. Res. Nat. Bur. Stand. (U.S.). 71C(3): 179-198; 1967 July-August.

[3] Bowman, H.A.; Gallagher, W., Schoonover, R. The development of a working density standard. Inst. Soc. of Amer., 20th Annual ISA Conference and Exhibit, October 4-7, 1965 Los Angeles, Preprint No. 14.8-4-65.

[4] Bowman, H.A., Schoonover, R.M., Carroll, L.C. A density scale based on solid objects. J. Res. Nat. Bur. Stand. (U.S.]. 78A(1): 13-40; 1974 January-February.

[5] Foulck, C.W. A new form of precision hydrometer. J. Opt. Soc. of Amer. and Rev. Sci. Instrum. 7(3): 327-334; 1923.

[6] Franklin, A.D.; Spal, R. A method for the precision comparison of the densities of small specimens. Rev. Sci. Instrum. 42(12): 1827$1833 ; 1971$.

[7] Schoonover, R.M.; Jones, F.E. Air buoyancy correction in high accuracy weighing on analytical balances. Anal. Chem. June 81.

[8] International critical table of numerical data, Physics, Chemistry and Technology. Volume III, 1928, page 27.

[9] Ogburn, F.E.; Schoonover, R.M.; Johnson, C.E. Plating and Surface Finishing, 68(42), March 1981.

[10] Biometrika Tables for Statisticians, Vol. I, edited by E.S. Pearson and O.H. Hartley, The University Press, Cambridge, 1958. 
[11] Bowman, H.A., Schoonover, R.M. Cartesian diver as a density comparator. J. Res. Nat. Bur. Stand. (U.S.). 69C(3): 217-223; 1965 July-September.

[12] Davis, R.S. J. Res. Nat. Bur. Stand. (U.S.). 87(3); ; 1982 May-June.

[13] Moldover, M.R.; Cohn, F. An interface phase transition: Complete to partial weighing, Science V-1 207: 1073-1075; 1980. 